\title{
Dietary Status in Albanian Patients with Rheumatoid Arthritis
}

Teuta Backa

University Hospital Centre: "Mother Theresa", Rheumatology Department, Tirana, Albania

Enkelejda Shkurti

Faculty of Technical Medical Sciences, University of Medicine, Tirana, Albania

Ergeta Ktona

Faculty of Technical Medical Sciences, University of Medicine, Tirana, Albania

Artur Zoto

University Hospital Centre: "Mother Theresa", Rheumatology Department, Tirana, Albania

Ervin Rrapushi

University Hospital Centre: "Mother Theresa”, Rheumatology Department, Tirana, Albania

Anila Troci

University Hospital Centre: "Mother Theresa”, Rheumatology Department, Tirana, Albania

Doi:10.5901/ajis.2014.v3n6p53

\section{Abstract}

Background: Atherosclerosis in patients with Rheumatoid Arthritis (RA) may be exacerbated by obesity. Aim: To investigate the dietary conditions of patients with RA. Methods: This cross-sectional study comprised 105 patients with RA in the department of Rheumatology of the University Hospital Centre: "Mother Theresa", in Tirana, Albania. They were examined for demographic, medical activity and dietary conditions. Finally, we assessed the measurement of body mass index (BMI), waisthip ratio; triceps skin fold measure (TSF) and its capability bicipital skin fold (BSF) and their sufficiency and arm muscle circumference (AMC) and its satisfactoriness. Allied studies of nominal records were done using Fisher and chi-square test. Unpaired Student $t$ tests and Mann Whitney were applied for numerical data. The Spearman test was exploited for correlation estimates. Results: There were 13/105 men, 92/105 women included in the survey. The mean age was $53.2 \pm 10.8$ years and mean illness extent of $10.4 \pm 7.51$ years in the whole sample. The mean waist-hip percentage was $0.89 \pm 0.08$. Along with BMI $28.6 \%$ had normal weight; $63.8 \%$ an overall weight more than normal. In relation to BSF, $71.6 \%$ were normal and $25.5 \%$ had reduction of muscular mass; in proportion to TSF, $79.3 \%$ were normal and $15.2 \%$ diminished. Alliance of dietary variables with sex, rheumatoid factor, age, nodules, and illness activity demonstrated no dissimilarities ( $p=N S)$ apart from a lower waist/hip proportion in patients with nodules $(p=0.01)$ and a diffident correlation of TSF with malady length $(p=0.01 ; R=0.18 ; 95 \% \mathrm{Cl}$ $=0.01$ to 0.30). Conclusion: We discovered a high prevalence of overweight and obesity in patients with RA and a little occurrence of muscle diminution.

\section{Introduction}

Rheumatoid arthritis (RA) is a persistent, progressive, inflammatory disease distinguished by proportioned, destructive polyarthritis and is related to universal symptoms, consisting of tiredness and cachexia. (1-4). It is the most widespread appearance of inflammatory polyarthritis (IP), with a global prevalence in adults of almost $1 \%$ (5). RA involves women more frequently than men by a fraction of $3: 1$. Even though the age of commencement in women is in the sixth decade, it can arise at any age. The etiology of rheumatoid arthritis (RA), remains mainly unidentified, even if microbiological, immune, genetic, hormonal, and nutritional features have been involved in its pathogenesis (6) 
RA is one of the more frequent autoimmune syndromes, which exceeds a number of other situations, comprising psoriasis, Crohn's disease, Type I (insulin-dependent) diabetes, lupus, and multiple sclerosis $(7,8)$

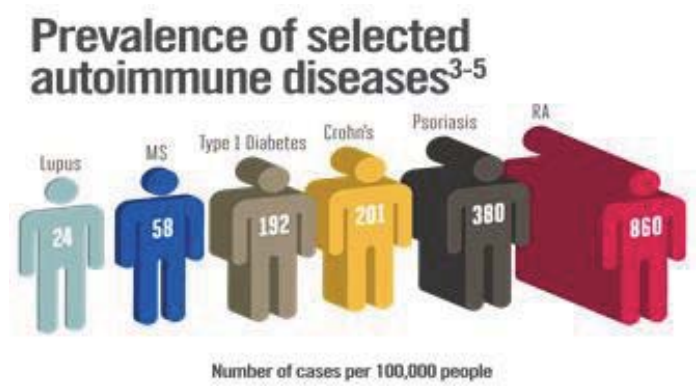

There is an amplified risk for cardiovascular episodes which is correlated with $(9,10)$ a diminished life expectancy $(10)$ in patients with RA. They have a fourfold increased frequency of acute myocardial infarction (11).

The pathogenesis of accelerated coronary (12)and extra coronary (13) atherosclerosis as an attribute of RA has not been evidently described (14) and the pathogenesis has not been evidently described (14). This pathogenesis is influenced by the high prevalence of conventional cardiovascular risk factors and the general inflammatory procedure. Work absence, premature retirement and financial failures $(15,16,17)$ are the outcome of combined pain and exhaustion connected with the inflammatory progression, malformations that obstruct the presentation of daily activities. Accelerated atherosclerosis by the persistent inflammatory course with successive cardiovascular consequences engages an outstanding role amid the reasons of enhanced mortality in these patients $(18,19,20)$. It has been distinguished through the previous decade, that RA relates with distorted body composition, differentiated by decreased lean mass and frequently maintained or augmented fat mass, linked with preserved or bigger body mass index (BMI) (21), a circumstance supposed to speed up morbidity and mortality in RA (22). While adjusting for co morbidity and RA harshness, survival benefit detected in obese patients with RA corresponding to individuals with the lowest BMI was lost (23). It is pointed out that raised BMI defends the joints by the surveys of the impact of BMI on joint demolition. Consequently, patients with early RA and a BMI $\geq 27 \mathrm{~kg} / \mathrm{m} 2$ had a reduced amount of continuous joint obliteration over 2 years than those with a $B M l<27 \mathrm{~kg} / \mathrm{m} 2$ (24). It is assessed that a RA patient is 1.5 to 2 times more expected to have myocardial infarction than the common people. This hazard is analogous to that of a patient with diabetes mellitus type 2 and can be enhanced by the habitual risk factors like obesity (25). In this perspective, one can conclude that dietary factors should be revised and cured in RA, considering the genetic consignment and lifestyle of the population. In the current work we investigated the dietary condition of patients with RA in Albanian population.

\section{Methods}

This is a cross-sectional survey accepted by the Scientific Board of the Faculty of Medicine, Tirana, Albania; where all the subjects signed the informal agreement. The participants met no less than four of the categorization principles for a diagnosis of RA of the American College of Rheumatology 1987(17) aged among 17 and 78 years old. There were left out pregnant women and persons with uninhibited hypothyroidism.

The staff of the project was trained to carry out the anthropometric measurements like body weight, height, waist circumference, hip circumference, arm circumference, biceps and triceps skin folds. The weight and height measurement were achieved by applying a digital balance Mars $₫$ and a stadiometer Cardiomed $₫$ correspondingly. The body mass index (BMI) was estimated by splitting weight in kilograms by height in squared meters (26). An inelastic anthropometric strip in relation to the Cuppari technique (27) was utilized to measure the circumferences of the hip, arm and waist. Prior to standardized procedures illustrated by Cuppari(27) were performed the dimensions of skin fold thickness of biceps and triceps with a Cescorf® caliper. The appraisal of skin folds capability was illustrated by Frisancho (28) and affirms that the patient is in harsh undernourishment when the sufficiency of arm muscle circumference is below $70 \%$, with restrained malnutrition when it is among $70 \%$ and $80 \%$, with soft malnutrition when amid $80 \%$ to $90 \%$ and euthrophic when above $90 \%$.

Health evidences of patients were appraised to acquire demographic and medical statistics, illness extent, and autoantibody outline such as rheumatoid factor (RF), malady activity (calculated by DAS28 4v) (29, 30). Data were gathered on the occurrence and contingency tables. We applied the Fisher and chi-square tests for association studies of 
nominal data, and Mann Whitney and unpaired Student $t$ tests was performed for numerical data. The Spearman test was utilized for correlation estimates. The computations were made using SPSS 20.0 for Windows.

\section{Results}

There were 13(13.7\%) men and 92 (86.2\%) women from the total of 105 patients, aged from 23 to 80 years (mean $53.2 \pm$ 10.8 years). The age at diagnosis was among 20 and 69 years (mean $40.7 \pm 11.6$ years) and malady extent amid 1 and 35 years (median 8 years; IQI = 5-13,8). Rheumatoid nodules were noticed in $9.6 \%$ of the participants. Rheumatoid factor was affirmative in $64.8 \%$. The DAS28 varied from 0.68 to 7.76 (mean $3.49 \pm 1.48$ ) and demonstrated that $15.8 \%$ of individuals had elevated activity, $31.4 \%$ had restrained activity, $21.2 \%$ had little activity and $27.8 \%$ were in RA reduction. An investigation of therapies illustrated that $72.9 \%$ were on glucocorticoid (dose: $2.5 \mathrm{mg}$ to 60 mg/prednisone/day; median $9 \mathrm{mg}$ ), $63.7 \%$ applied methotrexate, $43.7 \%$ antimalarial; $28.6 \%$ leflunomide; $14.3 \%$ biological therapy (13/105 anti TNF-a and 1/105 abatacept); $10.3 \%$ sulphasalazine and 2.6\% azathioprine.

The BMI of patients ranged among 16.0 and $45.5 \mathrm{~kg} / \mathrm{m} 2$ (mean of $27.9 \pm 5.7 \mathrm{~kg} / \mathrm{m} 2$ ). The BMl allocation in the sample could be realized in Fig. 1, which explained that the majority of patients were beyond the acknowledged weight. The survey of the connection among waist and hip dimensions confirmed values among 0.75 and 1.14 (mean $0.92 \pm$ 0.07). In 11/102 (10.7\%), the waist hip ratio went beyond 1.0. Concerning arm circumference capability, we examined that it varied from $68.6 \%$ to $136.2 \%$ (mean $99.9 \pm 13.7 \%$ ), and in proportion to this, $74.5 \%$ of the individuals were eutrophic, $24.5 \%$ had soft depletion and $0.98 \%$ had harsh muscle reduction. The study of triceps skin fold sufficiency demonstrated values amid 24.4\% and 336.4\% (median 94.4\%; IQI = 66.7-112.6). The delivery of findings concerning triceps skin fold capability could be seen in Fig. 2, that confirmed half of patients have some grade of exhaustion. The examination of arm muscle circumference sufficiency demonstrated values among $76.7 \%$ and $142.4 \%$ (mean $103.3 \pm$ $14.2 \%$ ). Regarding this assessment $83.3 \%$ of the population was eutrophic, $12.7 \%$ had soft depletion and $4 \%$ had restrained depletion.

There wasn't discovered any relation/correlation between BMI, waist-hip ratio, brachial skin fold adequacy, triceps skin fold sufficiency and capability of arm muscle circumference with participants sex, occurrence of rheumatoid factor, age, malady activity measured by DAS28 $4 \mathrm{v}$ and application of glucocorticoids ( $p=$ NS). Patients without nodules have an elevated significance of waist-hip $(p=0.02)$. There was a reserved correlation among triceps skin fold capability and disease extent $(p=0.02 ; R=0.22 ; 95 \% \mathrm{Cl} 0.01$ to 0.40$)$.

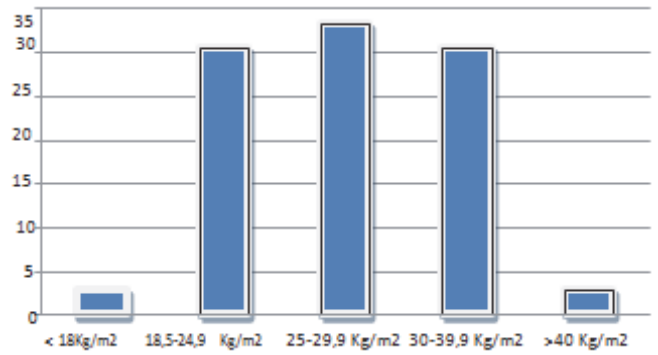

Fig. 1 - Prevalence (in \%) of body mass index (BMI) in 105 patients with RA.

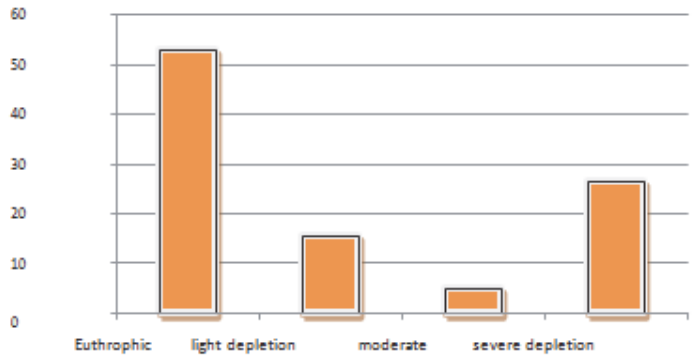

Fig. 2 - Delivery of discoveries of triceps skin fold capability (in \%). Analysis of 105 RA patients 


\section{Discussion}

The outcomes of this survey has demonstrated that the majority of patients with RA has been beyond normal weight. This is an surveillance previously made by other investigators: a multicenter survey confirmed a prevalence of obesity in $18 \%$ of RA patients (31) An additional survey, performed in England gave a higher prevalence, of 31\%(32). In these surveys equally over $60 \%$ of participants had an upper than preferred weight. Furthermore, we have noticed in the current examination that, despite the augmented BMI, nearly all patients had standard or reduced triceps skin fold. Augmented $\mathrm{BMI}$ has been detected at the expense of adipose tissue before muscle achievement by the present results. There are numerous aspects that contribute to an enlarged body fat and a diminished muscle accumulation in a patient with RA. Certainly, the inactivity enforced by a hurting and crippling joint illness has to be emphasized (33). First inactivity lessens energy spending, afterward it guides to muscle deterioration. Another causal issue is the application of drugs such as glucocorticoids that cause bigger appetite and fat increase (34). Enlarged body mass has significant repercussions for these patients, despite the etiology. Initially it is the automatic burden forced on the joints, particularly those of the lower limbs, which are previously deteriorated by constant inflammation (35) They will undergo structural injure more effortlessly guiding to minor osteoarthritis. Even though in RA atherosclerotic malady is mainly secondary to inflammation, it also suffers influence of traditional risk factors including obesity(36). The sum of traditional risk factors and inflammation will increase the chance of stroke and myocardial infarction.

According to Kremers et al (37) obesity increases 10-fold the risk of a cardiovascular event in patients with RA. The function of adipose tissue on the inflammatory development is a third repercussion. Generally, elevated levels of adipokines are the base of the enhancement in the inflammatory procedure in such a way that obesity is presently distinguished as a pro inflammatory condition (36). Distorted serum adipokine levels are correlated with rheumatoid arthritis (38). Obesity for itself is related with augmented hazard of developing RA (38) regarding several authors.

Nevertheless data in this last topic are opposing $(37,39)$. It was not noticed association of the application of glucocorticoid with dietary condition. It is recognized from literature that this drug is correlated with weight achievement and augmented abdominal fat deposition (40). As it is typically done in rheumatoid arthritis, the justification for this result is that the majority of our patients were using little doses of this drug. The association with growing glucocorticoid revelation could suggest additional information, but regrettably we did not have it. While we used only skin folds as a measurement of dietary condition, it can be perceived as a restriction; surveys with DEXA could recommend supplementary information. In summary, it can be stated that there is a weight grow in individuals with RA regardless of the loss of muscle accumulation, generally at the expense of adipose tissue. Obesity accumulation must be correctly thought about so as to best treat patients with this malady.

\section{References}

Roubenoff R. Rheumatoid cachexia: a complication of rheumatoid arthritis moves into the 21st century. Arthritis Res Ther. $2009 ; 11: 108$. Summers GD, Deighton CM, Rennie MJ, et al. Rheumatoid cachexia: a clinical perspective. Rheumatology. 2008; 47: 1124-1131.

Summers GD, Metsios GS, Stavropoulos-Kalinoglou A, et al. Rheumatoid cachexia and cardiovascular disease. Nat Rev Rheumatol. 2010; 6: 445-451.

Engvall IL, Elkan AC, Tengstrand B, et al. Cachexia in rheumatoid arthritis is associated with inflammatory activity, physical disability and low bioavailable insulin-like growth factor. Scand J Rheumatol. 2008; 37: 321-328.

Abdel-Nasser AM, Rasker JJ \& Valkenburg HA (1997) Epidemiological and clinical aspects relating to the variability of rheumatoid arthritis. Seminars in Arthritis and Rheumatism 27, 123-140

Linos A, Kaklamanis E, Kontomerkos A, et al. The effect of olive oil and fish consumption on rheumatoid arthritis: a case control study. Scand J Rheumatol 1991;20:419-26.

Jacobson DL, Gange SJ, Rose NR, Graham NMH. Epidemiology and Estimated Population Burden of Selected Autoimmune Diseases in the United States. Clinical Immunology and Immunopathology 1997;84:223-43

Gelfand JM, Weinstein R, Porter SB, Neimann AL, Berlin JA, Margolis DJ. Prevalence and treatment of psoriasis in the United Kingdom: a population-based study. Arch Dermatol 2005;141:1537-41.

Chung CP, Oeser A, Solus JF, Avalos I, Gebretsadik T, Shintani A et al. Prevalence of the metabolic syndrome is increased in rheumatoid arthritis and is associated with coronary atherosclerosis. Atherosclerosis 2008; 196(2):756-63.

Karvounaris SA, Sidiropoulos PI, Papadakis JA, Spanakis EK, Bertsias GK, Kritikos HD et al. Metabolic syndrome is common among middle-to-older aged Mediterranean patients with rheumatoid arthritis and correlates with disease activity: a retrospective, crosssectional, controlled, study. Ann Rheum Dis 2007; 66(1):28-33.

Del Rincon ID, Williams K, Stern MP, Freeman GL, Escalante A. High incidence of cardiovascular events in a rheumatoid arthritis cohort not explained by traditional cardiac risk factors. Arthritis Rheum 2001; 44(12):2737-45.

Dessein PH, Joffe BI, Stanwix AE, Christian BF, Veller M. Glucocorticoids and insulin sensitivity in rheumatoid arthritis. J Rheumatol 
2004; 31(5):867-74.

Chung CP, Oeser A, Solus JF, Avalos I, Gebretsadik T, Shintani A et al. Prevalence of the metabolic syndrome is increased in rheumatoid arthritis and is associated with coronary atherosclerosis. Atherosclerosis 2008; 196(2):756-63.

Karvounaris SA, Sidiropoulos PI, Papadakis JA, Spanakis EK, Bertsias GK, Kritikos HD et al. Metabolic syndrome is common among middle-to-older aged Mediterranean patients with rheumatoid arthritis and correlates with disease activity: a retrospective, crosssectional, controlled, study. Ann Rheum Dis 2007; 66(1):28-33.

La Montagna G, Cacciapuoti F, Buono R, Manzella D, Mennillo GA, Arciello A et al. Insulin resistance is an independent risk factor for atherosclerosis in rheumatoid arthritis. Diab Vasc Dis Res 2007; 4(2):130-5.

Da Mota LMH, Cruz BA, Brenol CV, Pereira IA, Rezende-Fronza LS, Bertolo MB et al. Guidelines for the drug treatment of rheumatoid arthritis. Rev Bras Reumatol 2013; 53: 158-83.

Kvien TK, Scherer HU, Burmester G-R. Rheumatoid Arthritis. In Bijlsma JWJ (ed) EULAR compendium on Rheumatic Diseases. BMJ Publishing Group Ltd, Italy, 2009, p.61-80.

Jeppesen J. Low-grade chronic infl ammation and vascular damage in patients with rheumatoid arthritis: don't forget "metabolic infl ammation". J Rheumatol 2011; 38: 595-7.

Popa C, van den Hoogen FH, TR Radstake, Netea MG, Eijsbouts AE, den Heijer M et al. Modulation of lipoprotein plasma concentrations during long-term anti-TNF therapy in patients with active rheumatoid arthritis. Ann Rheum Dis $2007 ; 66$ :1503-7.

Elkan AC, Engvall IL, Cederholm T, Hafstrom I. Rheumatoid cachexia, central obesity and malnutrition in patients with low-active rheumatoid arthritis: feasibility of anthropometry, Mini Nutritional Assessment and body composition techniques. Eur J Nutr 2009;48:315-22.

Walsmith J, Roubenoff R. Cachexia in rheumatoid arthritis. Int J Cardiol 2002;85:89-99.

Escalante A, Haas RW, del Rincon I. Paradoxical effect of body mass index on survival in rheumatoid arthritis: role of comorbidity and systemic inflammation. Arch Intern Med 2005;165: 1624-9.

Kaufmann J, Kielstein V, Kilian S, Stein G, Hein G. Relation between body mass index and radiological progression in patients with rheumatoid arthritis. J Rheumatol 2003;30: 2350-5.

Pereira IA, da Mota LMH, Cruz BA, Brenol CV, Rezende- Fronza LS, Bertolo MB et al. 2012 Brazilian Society of Rheumatology Consensus on the management of comorbidities in patients with rheumatoid arthritis. Rev Bras Reumatol 2012; 52: 474-95.

Brazilian Society of Endocrinology and Metabolism: Calculate your BMI. Available at: http://www.endocrino.org.br/conteudo/publico/imc. php. Captured in August 2011

Cuppari L. Nutritional Assessment. In: Cuppari G (ed). Clinical Nutrition in Adult. 2nd ed. São Paulo: Manole, 2006. p 89-127

Frisancho, AR. Anthropometric standards for the assessment of growth and nutritional status. The University of Michigan Press, 1990

Mäkinen H, Kautiainen H, Hannonen P, Sokka T. Is DAS-28 an appropriate tool to ASSESS remission in rheumatoid arthritis? Annals Rheum Dis 2005, 64:1410-1413.

Fransen J, van Riel PLCM. DAS remission cut points. Clin Exp Rheumatol 2006; 24 (S-43): S29-S32.

Naranjo A, Sokka T, Descalzo MA et al. Cardiovascular disease in patients with rheumatoid arthritis: results from the QUEST-RA study. Arthritis Res Ther 2008, 10: R30

Armstrong DJ, McCausland EM, Quinn DA, Wright GD. Obesity and cardiovascular risk factors in rheumatoid arthritis. Rheumatology 2006, 45: 782-3.

Bray GA, Bellanger T. Epidemiology, trends, and morbidities of obesity and the metabolic syndrome. Endocrine 2006; 29: 109-17.

Peckett Ajm DC Wright, Riddell MC. The effects of glucocorticoids on adipose tissue lipid metabolism. Metabolism 2011; 60:1500-10.

Hollingworth P, Melsom RD, Scott JT. Measurement of radiographic joint space in the rheumatoid knee: correlation with obesity, disease duration, and other factors. Rehabil Rheumatol 1982, 21: 9-14.

Stavropoulos-Kalinoglou A, Metsios GS, Koutedakis Y, Kitas GD. Obesity in rheumatoid arthritis. Rheumatology 2011; 50:450-462.

Kremers HM, Crowson CS, Therneau TM, Roger VL, Gabriel SE. High ten-year risk of cardiovascular disease in newly diagnosed patients with rheumatoid arthritis: a population based cohort study. Arthritis Rheum 2008, 58: 2268-74.

Hayashi H, Satoi K, Sato-Mito N, Kaburagi T, Yoshino H, Higaki M et al. Nutritional Status in relation to adipokines and oxidative stress is associated with disease activity in patients with rheumatoid arthritis. Nutrition 2012, 28:1109-14.

Symmons DP, Bankhead CR, Harrison BJ, Brennan O, Barrer EM, Scott DG et al. Blood transfusion, smoking, obesity and the risk factors for the development of rheumatoid arthritis: results from a primary care-based incident case-control study in Norfolk, England. Arthritis Rheum 1997, 40: 1955-61.

Buttgereit F, Spies C, Kirwan J. Glucocorticoids. In Bijlsma JWJ (ed) EULAR compendium on Rheumatic Diseases. BMJ Publishing Group Ltd, Italy, 2009, p.601-15. 
